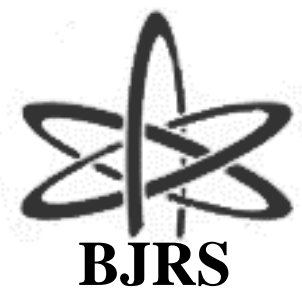

BRAZILIAN JOURNAL

$\mathrm{OF}$

RADIATION SCIENCES

09-02B (2021) 01-13

\title{
Scientific knowledge management about Monte Carlo method: a bibliometric analysis on IRD Postgraduate Program in Radiation Protection and Dosimetry
}

\author{
Amorim $^{a}$ F. do C., Filho ${ }^{b}$ P. P. de Q., Razuck ${ }^{b}$ F.B. \\ ${ }^{a}$ Centro Federal de Educação Tecnológica / Departamento de Engenharia Mecânica, CEFET/RJ, UnED, Itaguaí, Rio \\ de Janeiro, Brazil \\ ${ }^{b}$ Institute of Radiation Protection and Dosimetry, 2278-127, Rio de Janeiro, Brazil
}

fernandor@ird.gov.br

\begin{abstract}
With technological advances in several research areas of science, it is becoming increasingly common to use computer programs to solve problems. Some of these programs are based on statistical analysis and simulation of reality, such as the Monte Carlo Method (MC). The MC is a statistical tool widely used in different areas of knowledge, as a resource for simulating events that involve from financial assessments to the interaction of radiation with matter. Thereby, surveys with radiation sources, for example, are constantly evolving to study the question of radiation protection. In this sense, this paper has as main objective to verify the relevance of the MC for the area of radiation protection, analyzing the studies that apply the method in the Postgraduate Program (PPG) in Radiation Protection and Dosimetry of Institute of Radiation Protection and Dosimetry (IRD). This is because it is understood that through the application of Scientific Knowledge Management (SKM) the construction of knowledge happens through an exchange of scientific information, that is, exchange of relevant contents that help in the preservation of knowledge. In this sense, a bibliometric analysis was performed, evaluating the dissertations and theses (D\&T) deposited at the Catalog of Thesis and Dissertations (CTD) of the Coordination for the Improvement of Higher Education Personnel (Capes) to analyze the researches about MC and its respective programs (PENELOPE, GEANT4, EGSnre, MCNP and Visual Monte Carlo) on PPG of IRD.
\end{abstract}


With the identification of works carried out in all areas of concentration of the PPG, it is understood that the $\mathrm{MC}$ is extremely relevant for studies in the area of radiation protection.

Keywords: Institute of Radiation Protection and Dosimetry, Postgraduate Program in Radiation Protection and Dosimetry, Bibliometric Analysis, Catalog of Dissertations and Thesis, Monte Carlo Method, Scientific

Knowledge Management.

ISSN: 2319-0612

Accepted: 2021-02-09 


\section{INTRODUCTION}

\subsection{Presentation}

It can be said that radiation and its ability to interact with matter can be divided into two main groups, in relation to the energy range: a) Ionizing radiation - that has enough energy to release electrons from an atom, thus making the atom charged; and b) Non-ionizing radiation - for instance, UV rays, visible light, that does not hold enough energy to pull electrons out [1].

The radioactive sources, that emit ionizing radiation from the nucleus of atoms, can be natural or artificially produced, is applied in a wide area: it ranges from health treatments to energy generation. Thus, the study of ionizing radiation is extremely important, so that the knowledge of its applications, as well as its damages, are better understood. [1].

In this way, the use of radiation and research on radioactivity are constantly evolving. Thereby, researches about radiation sources, for example, are being carried out to study the question of radiation protection [2].

With advances in several sectors of science, it is becoming increasingly common to use computer programs to solve problems. For example, dosimetry calculations and measurements, which are recurrent operations in the metrology of ionizing radiation, have become more efficient with the use of computers, since they have made possible the simulation of laboratory experiments [3].

Then, with the development of computational codes to simulate the interaction of radiation with matter, advances were possible in this field of study. With simulation programs it is possible to create different scenarios and geometries, where the only limiting factor is the computational power of the operator's machine. Some of these programs are based on statistical analysis and simulation of results, as the Monte Carlo Method (MC) [3].

\subsection{The Monte Carlo Method}

The MC is a statistical tool widely used in several areas of knowledge, and can be applied in studies ranging from the simulation of events involving financial assessments to the interaction of radiation with matter [3]. 
Although the initial ideas for applying the method date back to the 16th century, its application became possible with the advent of computing. The first noteworthy application occurred in the project of controlled energy production through nuclear fission, during the Second World War [4].

$\mathrm{MC}$ is an interesting tool to solve highly complex problems involving the issue of nuclear material. In the study of particle transport, for example, the MC consists of following each of the numerous particles along their path to some final event, such as absorption, escape, etc. [4].

A lot of researches in the area could be simulated with the use of MC, such as calculations of correction factors for ionization chambers and radiation dosimetry in anthropomorphic or voxel phantoms. In many experimental works with good results, the MC technique could have been applied, generating new relevant results for publication [5]. Some of the main codes used in the simulation of the interaction of radiation with matter are, for instance: MCNP, PENELOPE, EGSnrc, GEANT4 and Visual Monte Carlo [5-11].

\subsection{The Scientific Knowledge Management}

It can be affirmed that the understanding of the scientific knowledge itself, by an institution of teaching and research, ultimately promotes advances in its activities. Thus, the organization of knowledge and its consequent access becomes a major initiative for this effort [12].

In this sense, the organization of scientific knowledge reflects the history of local science, in terms of conceptual interactions, defining structural patterns of social and scientific relations. Thus, the understanding and organization of scientific knowledge help to organize the local structure, assisting in technological innovation [12].

In this way, one of the applications of scientific knowledge occurs through scientific knowledge management (SKM). SKM generally addresses the planning and control of actions that govern the flow of scientific knowledge, having as substrates the processes of scientific communication in order to support and maximize the creation of new knowledge and teaching [13].

An example of SKM would be the study of thesis and dissertations from a Postgraduate Program (PPG) of a research institution, since all publications were deposited in the form of scientific communication. 


\section{MATERIALS AND METHODS}

In this sense, this paper has as main objective to verify the relevance of the MC for the PPG in Radiation Protection and Dosimetry of Institute of Radiation Protection and Dosimetry (IRD).

A bibliometric analysis was then performed, evaluating the dissertations and theses (D\&T) deposited at the Catalog of Thesis and Dissertations (CTD) of the Coordination for the Improvement of Higher Education Personnel (Capes) to analyze the researches about MC on PPG of IRD.

This research was made searching the term "Monte Carlo" and its respective programs ("PENELOPE", "GEANT4", "EGSnrc", "MCNP" and "Visual Monte Carlo"), to be found in the title, abstract or keywords of D\&T.

The choice of the search for D\&T was due to the fact that these studies were identified as important resources of scientific and technological information, assisting as an indicator of the development of research area [14].

\section{RESULTS AND DISCUSSION}

According to CTD, there are 4,002 D\&T on "MC" + Radiation Protection. In relation to the "Multidisciplinary" area, which is the IRD assessment area within Capes, there are 382 D\&T, which corresponds to practically $9.6 \%$ of the total D\&T on MC [15].

By the end of the year 2018, the total of 195 D\&T of IRD had been deposited. However, the CTD provides, by concentration area, only the D\&T deposited from 2013, the year in which the Sucupira system of Capes was implemented.

Thus, the information prior to 2013 was obtained from the PPG Secretariat. The PPG is composed of the following areas of concentration: Radiation Biophysics, Medical Physics, Metrology and Radioecology.

From this scenario, the analysis of the publications was carried out (Tables 1,2 and 3 and Graphs 1, 2 and 3). After the bibliometric analysis of D\&T deposited in the CTD of Capes about $\mathrm{MC}$ in the IRD, it is possible to verify that: 
a) Table 1 presents the total panorama of distribution of the works of the PPG of the IRD between the years 2003-2018, considering the four areas of concentration: Radiation Biophysics, Medical Physics, Metrology and Radioecology;

b) Table 2 and Graph 1 show that the sum of D\&T that used the term "Monte Carlo" (or its programs) is around $15.89 \%$, indicating its relevance to the IRD. The "other" portion refers to the works that used only the MC method and the works that used programs developed by the advisor himself that appear in the search in the CTD;

c) Table 3 and Graph 2 show that, except for the Radioecology area, all other areas use the method. It also shows that the Metrology area is the most used method (about $30.95 \%$ of the D\&T); and

d) Graph 3 shows the number of D\&T during the years, so that it is not possible to show a tendency in the use of the technique.

Table 1: Number of D\&T per area of concentration/year of the IRD ${ }^{1}$.

\begin{tabular}{|c|c|c|c|c|c|c|c|c|c|c|c|c|c|c|c|c|c|c|c|}
\hline $\begin{array}{l}\text { Area of Concentration } \\
\text { /Year of Defense }\end{array}$ & ఠ్ & ఫ্ণ & ڤ్) & ঠั & હે̊ & 离 & ஓ્ন & 을 & $\overline{\overline{\mathcal{N}}}$ & 글 & 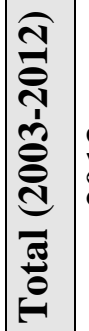 & $\stackrel{m}{\stackrel{\sim}{二}}$ & 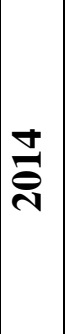 & $\frac{10}{8}$ & 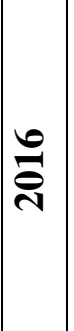 & 목 & $\stackrel{\infty}{\stackrel{\sim}{*}}$ & 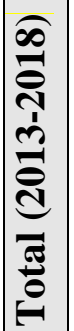 & 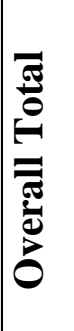 \\
\hline Medical Physics & 2 & 8 & 4 & 5 & 0 & 1 & 3 & 4 & 2 & 3 & 32 & 6 & 7 & 7 & 4 & 4 & 6 & 34 & 66 \\
\hline Metrology & 1 & 2 & 2 & 2 & 0 & 1 & 2 & 3 & 5 & 3 & 21 & 3 & 3 & 4 & 3 & 3 & 5 & 21 & 42 \\
\hline Radioecology & 4 & 5 & 6 & 3 & 2 & 3 & 3 & 0 & 1 & 2 & 29 & 1 & 7 & 0 & 2 & 2 & 4 & 16 & 45 \\
\hline $\begin{array}{l}\text { Radiation } \\
\text { Biophysics }\end{array}$ & 0 & 2 & 3 & 1 & 2 & 5 & 1 & 6 & 2 & 0 & 22 & 4 & 3 & 1 & 5 & 4 & 3 & 20 & 42 \\
\hline Total & 7 & 17 & 15 & 11 & 4 & 10 & 9 & 13 & 10 & 8 & 104 & 14 & 20 & 12 & 14 & 13 & 18 & 91 & 195 \\
\hline
\end{tabular}

Source: The author, 2019.

\footnotetext{
${ }^{1}$ The values are divided into 2 periods of different years: 2003 to 2012 and 2013 to 2018 . This is because the CTD of Capes only provides the values per concentration area from 2013, year of the implementation of the Sucupira system.
} 
Graph 1: Number of D\&T per area of concentration/year of the IRD.

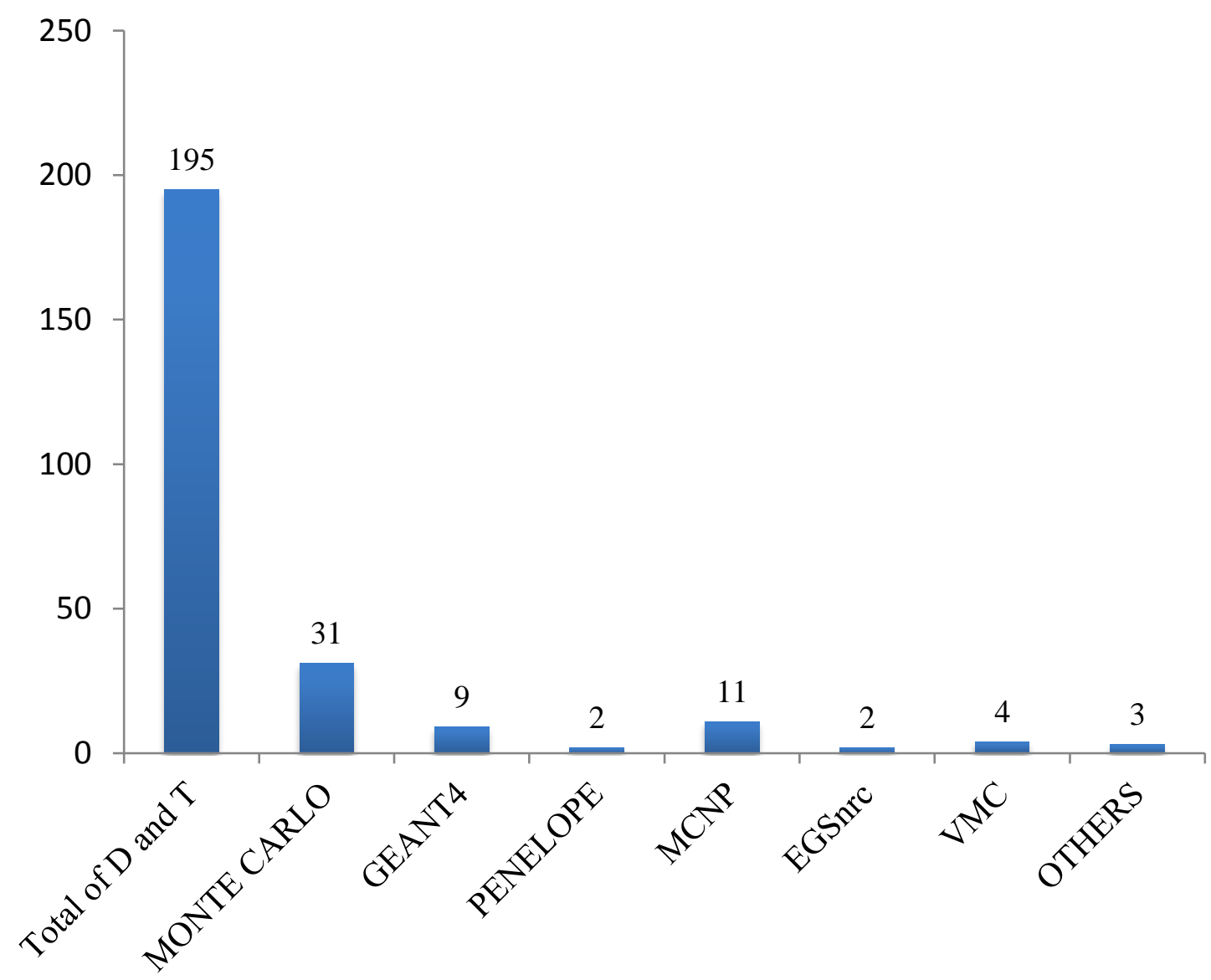

Source: The author, 2019.

Table 2: Number of D\&T per area of concentration/year of the IRD.

\begin{tabular}{c|l|l|l|l|l|l|l}
\hline $\begin{array}{c}\mathbf{N}^{\circ} \text { and \% } \\
\text { Total of }\end{array}$ & Monte & PENELOPE & GEANT4 & EGSnrc & MCNP & VMC & OTHERS \\
\hline
\end{tabular}




\begin{tabular}{c|c|c|c|c|c|c|c}
\hline D\& T & Carlo & & & & & & \\
\hline $195 / 100$ & $31 / 15,89$ & $2 / 1,03$ & $9 / 4,62$ & $2 / 1,03$ & $11 / 5,64$ & $4 / 2,05$ & $3 / 1,54$ \\
\hline
\end{tabular}

Source: The author, 2019.

Graph 2: Number of D\& T about MC in relation to the total of the defended in the different areas of concentration.

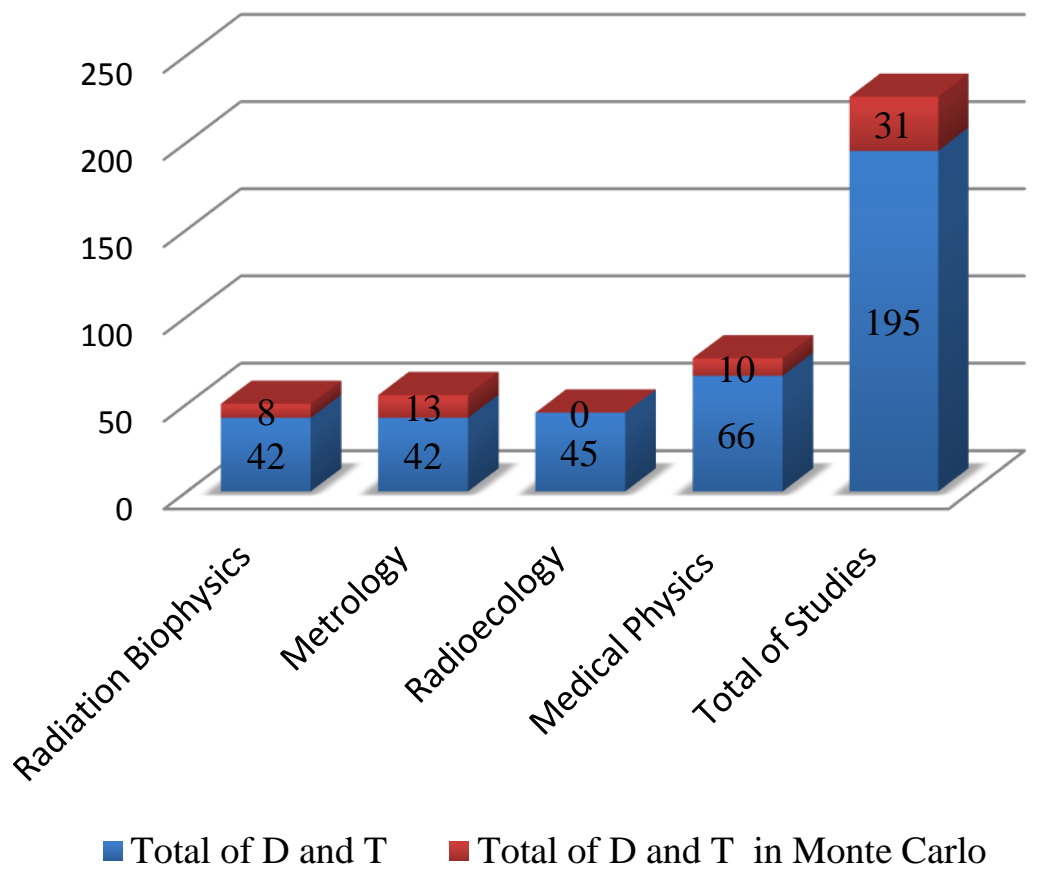

Source: The author, 2019.

Table 3: Number and \% of D\&T about MC in relation to the total of the defended in different areas of concentration. 


\begin{tabular}{c|c|c}
\hline Area of Concentration & Total $\mathbf{N}^{\circ}$ of D\&T & $\mathbf{N}^{\mathbf{o}}$ and \% of D\&T about MC \\
\hline Metrology & 42 & $13 / 30,95$ \\
\hline Medical Physics & 66 & $10 / 15,15$ \\
\hline Radiation Biophysics & 42 & $8 / 19,05$ \\
\hline Radioecology & 45 & $0 / 0$ \\
\hline Total & 195 & $31 / 15,89$ \\
\hline
\end{tabular}

Source: The author, 2019.

Graph 3: Number of D\& $T$ about MC in relation to the total of the IRD according to the year.

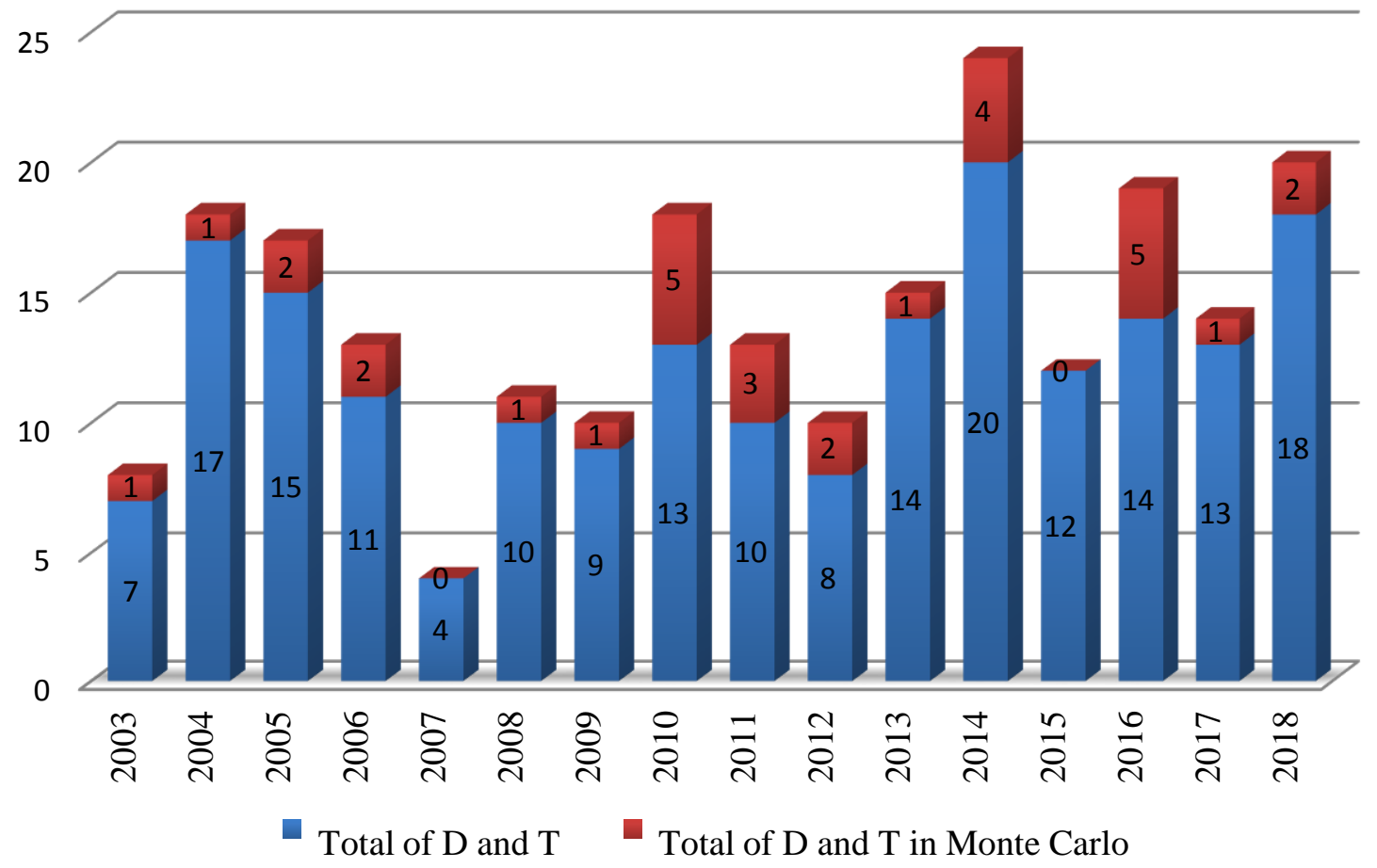

Source: The author, 2019.

In addition, it must be said that: 
1) The values may be underestimated, since the Sucupira only relates D\&T with the respective concentration areas from 2013, so that 104 of them (177 of the total of D\&T minus 91, which corresponds to the number of D\&T defended from 2013) did not are related to the concentration areas, so the previous data were obtained from the PPG Secretariat; and

2) In addition, even in the D\&T made available in the CTD (from 2013 forward) themselves present incomplete data regarding the areas of concentration.

\section{CONCLUSION}

The choice for the MC method is due to the fact that it is a tool with many applications in the area of radiation protection, dosimetry and metrology. Thus, the method allows, through the pseudo-random drawing of numbers whose main properties are a uniform distribution in the drawing and a very long repetition periodicity of the sequence, to simulate phenomena that occur in the interactions of radiation with matter.

The simulation of physical phenomena that are based on the behavior of, for example, a high number of particles subjected to an expressive number of processes is considered complex to implement due to the difficulty arising from the high number of events considered.

As verified in this paper, there was a significant number of works involving MC in the IRD, which demonstrates the importance of this method. The relevance of the MC for the PPG was verified in all the 4 (four) Concentration Areas, mainly to Metrology of Ionizing Radiation.

Although the MC is enshrined, being widely used in scientific research, it is understood that MC is still underutilized in the PPG of IRD, so that it is increasingly relevant to disclose its use and its applications within the scientific community for better application of the method.

It is also intended to perform an analysis in the library of the IRD of D\&T to verify the proportion of the total of those who used MC, since the Sucupira only provides the PDFs and relates the D\&T with the respective areas of concentration from 2013; create a pattern of information for the D\&T when sent to Capes, so that information such as the area of concentration, for example, are correct and with this it be comes clearer the data regarding the PPG; and analyze 
how D\&T in order to verify all that used but did not cite the method of MC, as well as that they did not use but would have potential for it.

Regarding the SKM, it can be said that few studies were found in Brazil and in the world, which is why the number of publications on the subject is still scarce. This demonstrates that it is a rising topic in the academic environment.

In addition, despite the work evaluating the scientific production of the IRD in relation to the MC (specifically on theses and dissertations), the focus was not necessarily to detail the different tools considered in the method, but rather to demonstrate how KM can be useful when applying your tools in the analysis of a particular line of research in a graduate program. So it is intended to expand this research to analyze the work in Brazil and in the world, since the initial idea was to apply the analysis through KM of the importance of MC for the PPG of IRD.

The idea of the paper was to evaluate the impact of MC on IRD's D\&T. It is intended, in the future, to evaluate the MC in the other programs, in the nuclear area, in the country (this will be placed in the conclusion).

With regard to the different codes of MC, it was decided to use them, to demonstrate to the lay public, that there are different languages and applications for MC.

In addition, it is intended to continue to carry out a quantitative and qualitative analysis of the productions in the area, we intend, in the future, to do a prospection of the defended works that could potentially have used MC.

From the observations made and starting from the premise that the MC has a great relevance for the research in the area, a proposal was also made for an introductory course in order to start the student of the area to have a first contact with the subject, by means of MC applications in mathematical operations and with the use of point and flat radiation sources.

Then, from the resultsof this research, it is understood that its developement may bring benefits and advances to the PPG of IRD. This is because it is understood that through the application of SKM the construction of knowledge happens through an exchange of scientific information, that is, exchange of relevant contents that help in the preservation of knowledge.

Moreover, the understanding of the dynamics of the scientific production of a giventhemeis of extreme relevance to the SKM, since it can serve as a basis for decision-making of students and teachers in relation to the themes of future dissertations and thesesregarding the use of MC; provide 
a strategic vision of the program based on keywords, titles and abstracts; andprovide a standard of inclusion in the keywords, title, and the future of the work.

\section{REFERENCES}

[1] UNEP. United Nations Environment Program. Radiation effects and sources, 2016.

[2] TAUHATA, L.; SALATI, I. P. A.; PRINZIO, R. DI; PRINZIO, M. A. R. R. DI. Fundamentos de Radioproteção e Dosimetria, 10ª revisão. IRD/CNEN, Rio de Janeiro, 2014.

[3] BEN, F.G. Análise estocástica da densidade espectral de nêutrons em um modelo de reator nuclear para avaliação da probabilidade local da fuga de nêutrons. Monografia (Graduação) - Departamento de Engenharia Mecânica - Universidade Federal do Rio Grande do Sul, 2012.

[4] SILVEIRA, M.F.; CAMPOS, T.P.R. Avaliação Radiodosimétrica através do Código MCNP-5 da Radiosteoplastia em Tumores Ósseos nos Membros. Revista Matéria, n.12 (1),186-192, 2007.

[5] BRIESMEISTER, J. F. MCNP - A General Monte Carlo N-Particle Transport Code. Los Alamos National Laboratory, Version 4C2, US, 2000.

[6] KAWRAKOW, I.; ROGERS, D. W. O. The EGSnrc code system: Monte Carlo simulation of electron and photon transport Technical Report PIRS-701. Ottawa: National Research Council of Canada, 2000.

[7] ROGERS, D. W. O.; KAWRAKOW, I.; SEUNTJENS, J. P.; WALTERS, B. R. B. NRC user codes for EGSnrc Technical Report PIRS-702. Ottawa: National Research Council of Canada, 2000.

[8] SAlVAT, F.; FERNANDEZ-VAREA, J. M.; ACOSTA, E.; SEMPAU, J.PENELOPE—a code system for Monte Carlo simulation of electron and photon transport. Workshop Proc. Issy-les-Moulineaux, France, 7-10 July. Paris: Organization for Economic Cooperation and Development, 2003. 
[9] HunT, J. G., CAVAlCANTI, E. G., DOS SAnTOS D. S., AZEREDO, A. M. G. Voxel phantoms and Monte Carlo methods applied to internal and external dose calculations. In. 11th International Congress of the International Radiation Protection Association, Madrid, IRPA - 11 Proceedings and Abstracts, 2004.

[10] HUNT, J. G., DANTAS B. M., AZEREDO, A. M. G. F. Visual Monte Carlo in-vivo in the CONRAD and IAEA Whole Body Counter Intercomparisons. In. Workshop on Uncertainty Assessment in Computational Dosimetry, Bologna, 2007.

[11] BOSCHETTI, S. R. Utilização e verificação do código GEANT4 em aplicações médicas: estudo de caso para eletróns. Dissertação de Mestrado - UFMG, 2013

[12] YI, S., CHOI, J. The organization of scientific knowledge: the structural characteristics of keyword networks. Scientometrics, v. 90, n. 3, p. 1016-1026, 2012. Gestão do conhecimento científico: proposta de um modelo conceitual com base em processos de comunicação científica

[13] LEITE, F. C. L.; COSTA, S. M. de S. Gestão do conhecimento científico: proposta de um modelo conceitual com base em processos de comunicação científica. Ci. Inf., v.36 n.1 Brasília Jan./Apr. 2007.

[14] RAZUCK, F.B.; RAZUCK, R. C. S. R.Conhecimentos produzidos acerca da comunicação científica em Bakhtin: uma incursão nas dissertações e teses brasileiras. Práxis, v. 10, p. 103$115,2018$.

[15] CTD. Catálogo de teses e dissertações. Capes. 2020. Disponible at: <https://catalogodeteses.capes.gov.br/catalogo-teses/\#!/>. Last acessed at 01/03/2020. 